\title{
Organ donation in the United States
}

\author{
Howard M. Nathan ${ }^{a}$, Suzanne L. Conrad ${ }^{b}$, Philip \\ J. Held ${ }^{c}$, Keith P. McCullough', Richard E. \\ Pietroski $^{\mathrm{d}}$, Laura A. Siminoff ${ }^{\mathrm{e}}$ and Akinlolu 0. \\ Ojo ${ }^{f_{*}}$
}

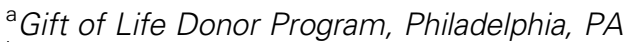

blowa Donor Network, lowa City, IA

'Scientific Registry of Transplant Recipients (SRTR)/

University Renal Research and Education Association

(URREA), Ann Arbor, MI

${ }^{\mathrm{T}}$ Transplantation Society of Michigan-Gift of Life, Ann

Arbor, MI

e Case Western Reserve University, Cleveland, $\mathrm{OH}$

${ }^{\mathrm{f}}$ SRTR/University of Michigan, Ann Arbor, MI

*Corresponding author: Akinlolu O. Ojo, aojo@umich.edu

\begin{abstract}
Key words: Consent, deceased donors, donation rates, living donors, OPOs, organ donation, organ procurement, SRTR
\end{abstract}

Received 17 September 2002, revised and accepted for publication 4 December 2002

\section{Introduction}

A review of organ donation in the United States must begin with an understanding of the system by which organs are procured. The first section of this article provides an overview of the organ procurement system, focusing on the processes and regional presence of organ procurement organizations (OPOs). The sections that follow provide first a historical review of legislative and regulatory efforts to improve organ donation and then an examination of trends in the recovery and disposition of organs.

Funding: The Scientific Registry of Transplant Recipients (SRTR) is funded by contract \#231-00-0116 from the Health Resources and Services Administration (HRSA). The views expressed herein are those of the authors and not necessarily those of the US Government.

This is a US Government-sponsored work. There are no restrictions on its use.

Note on Sources: The articles in this supplement are based on the reference tables in the 2002 OPTN/SRTR Annual Report, which are not included in this publication. Much relevant data appear in figures and tables directly referred to in the article; other tables from the Annual Report that serve as the basis for this article include the following: Tables 1.1-1.3, 2.1-2.8, 3.1-3.4, $3.6-3.10,3.12,3.13,3.15,3.16,3.18$, and 4.1 . All of these tables are also available online at http://www.ustransplant.org.
Though outnumbered by living donors for the first time in 2001, deceased donors still provide most transplanted organs. A detailed examination of the differences between the characteristics of living and deceased donors is reported here, followed by a discussion of deceased donors broken down by demographics and by organ recovered. The article concludes with an examination of an emerging trend in organ donation-the recovery of organs from nonheartbeating donors-and with a look at innovative new organ donation initiatives.

\section{Overview of the US Organ Procurement System for Cadaveric Organs}

The US organ procurement system comprises 59 OPOs, which provide all of the deceased donor organs for the nation's 287 transplant centers (Figure 1). Of the OPOs, 50 are independent (private, nonprofit organizations) and nine are hospital-based. Each OPO has a contiguous geographical service area designated by the Federal Government for recovering organs in all hospitals in that region. Since 1988, OPO designation has been carried out biannually by the Health Care Financing Administration (HCFA), now termed the Centers for Medicare and Medicaid Services (CMS), on the basis of organ recoveries and organ transplants performed. Beginning in 2002, OPO designations will be made every 4 years, due to changes in federal regulations.

Each OPO is required to be a member of the national Organ Procurement and Transplantation Network (OPTN), the maintenance of which has been contracted to the United Network for Organ Sharing (UNOS) since 1987. The rules for organ allocation are set by OPTN/ UNOS, and a computer algorithm for distribution of each type of organ is programmed to fulfill this function. All patients waiting for an organ from a deceased donor are required to be placed in the waiting list database. Current registrants number more than 81500 . Each time an organ is donated within an OPO service area, the allocation system matches the donor with the database of waiting transplant candidates. The system then generates an ordered list of the potential recipients based on the algorithm for that organ system. Each organ is then offered by the OPO in sequence by communicating the donor's medical and social history to the medical professional (most often the transplant surgeon) at the transplant center where that patient is wait-listed. The transplant center may accept or decline the organ on behalf of the candidate, based on the medical professional's judgment. Extrarenal organs are typically matched and allocated before 


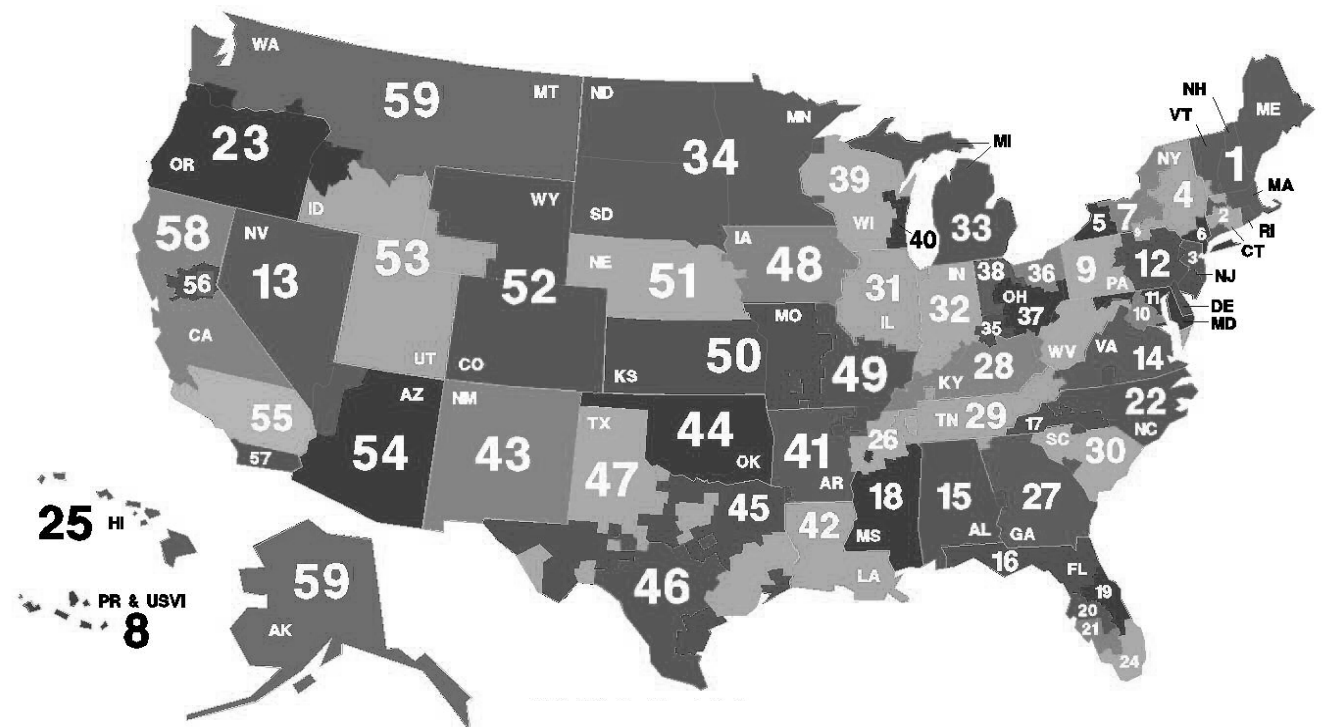

1. New England Organ Bank

2. LifeChoice OPO and Tissue Bank

3. NJ Organ and Tissue Sharing Network

4. Center for Donation and Transplant

5. Upstate New York Transplant Services

6. New York Organ Donor Network

7. Finger Lakes Donor Recovery Network

8. Lifelink of Puerto Rico

9. Center for Organ Recovery and Education

10. Washington Regional Transplant Consortium

11. Transplant Resource Center of Maryland

12. Gift of Life Donor Program

13. Nevada Donor Network

14. LifeNet

15. Alabama Organ Center

16. The OPO at the University of Florida

17. Life Share of the Carolinas

18. Mississippi Organ Recovery Agency

19. Translife/Florida Hospital

20. Lifelink of Florida
21. Lifelink of Southwest Florida 22. Carolina Donor Services

23. Pacific Northwest Transplant Bank

24. University of Miami OPO

25. Organ Donor Center of Hawail

26. Mid-South Transplant Foundation

27. Lifelink of Georgia

28. Kentucky Organ Donor Affiliates

29. Tennessee Donor Services

30. SC Organ Procurement Agency

31. Gift of Hope Organ and Tissue Donor Network

32. Indiana OPO

33. Transplantation Society of Michigan

34. Lifesource Upper Midwest OPO

35. Ohio Valley Life Center

36. Lifebanc

37. Lifeline of Ohio Organ Procurement

38. Life Connection of Ohio

39. University of Wisconsin Hospital and Clinic 40. Wisconsin Donor Network
41. Arkansas Regional Organ Recovery Agency

42. Louisiana Organ Procurement Agency

43. New Mexico Donor Services

44. Oklahoma Organ Sharing Network

45. Southwest Transplant Alliance

46. Texas Organ Sharing Alliance

47. Life Gift Organ Donation Center

48. lowa Donor Network

49. Mid-America Transplant Services

50. Midwest Transplant Network

1. Nebraska Organ Retrieval Service

52. Donor Alliance

53. Intermountain Organ Recovery Systems

54. Donor Network of Arizona

55. One Legacy OPO

56. Golden State Transplant Services

57. Life Sharing Community OPO \& Tissue Bank

58. California Transplant Donor Network

59. LifeCenter Northwest

Figure 1: Organ procurement organization service areas.

the organs are recovered in order to limit cold ischemic time. The organs are surgically recovered at the donor hospital and preserved in cold solution via static or pulsatile preservation for transport to the recipient's transplant center.

The current allocation algorithm prioritizes the matching patients in the local OPO service area, then regionally, then nationally (Figure 2). Policies for allocation also consider medical status (heart and liver), blood type, HLA tissue type (kidneys only), PRA (kidneys only), donor weight (nonrenal organs) and time spent on the waiting list. Additional points are given to children under age 18 and to candidates who have previously donated an organ (kidney); other organ-specific allocation rules also exist. Zero HLA-mismatched kidney candidates are given national priority regardless of their geographic location or points accrued. Status 1 liver registrants also are given priority within an OPTN/UNOS region over local candidates with less medical urgency.

\section{Organ procurement organization donor differences and geographic trends}

While the total number of deceased donors increased by $35 \%$ from 1992 to 2001, the increased recovery rate was not experienced uniformly across OPTN/UNOS regions. Over the last 10 years, many OPOs across the country experienced volatile rates of change in the numbers of deceased donors. For example, the OPO serving Alabama recovered organs from 116 deceased donors in 1998 but from only 85 donors the following year, a $27 \%$ decrease. In 2000, however, this rate jumped by $48 \%$ when the OPO recovered organs from 126 deceased donors, its best year to date. Such volatility is not uncommon in the organ procurement field.

A review of all transplant activity over a 10-year period affords some observations of typical activity by OPO and region. By OPTN/UNOS region, average total increases in deceased donors from 1992 to 2001 ranged from a low of 


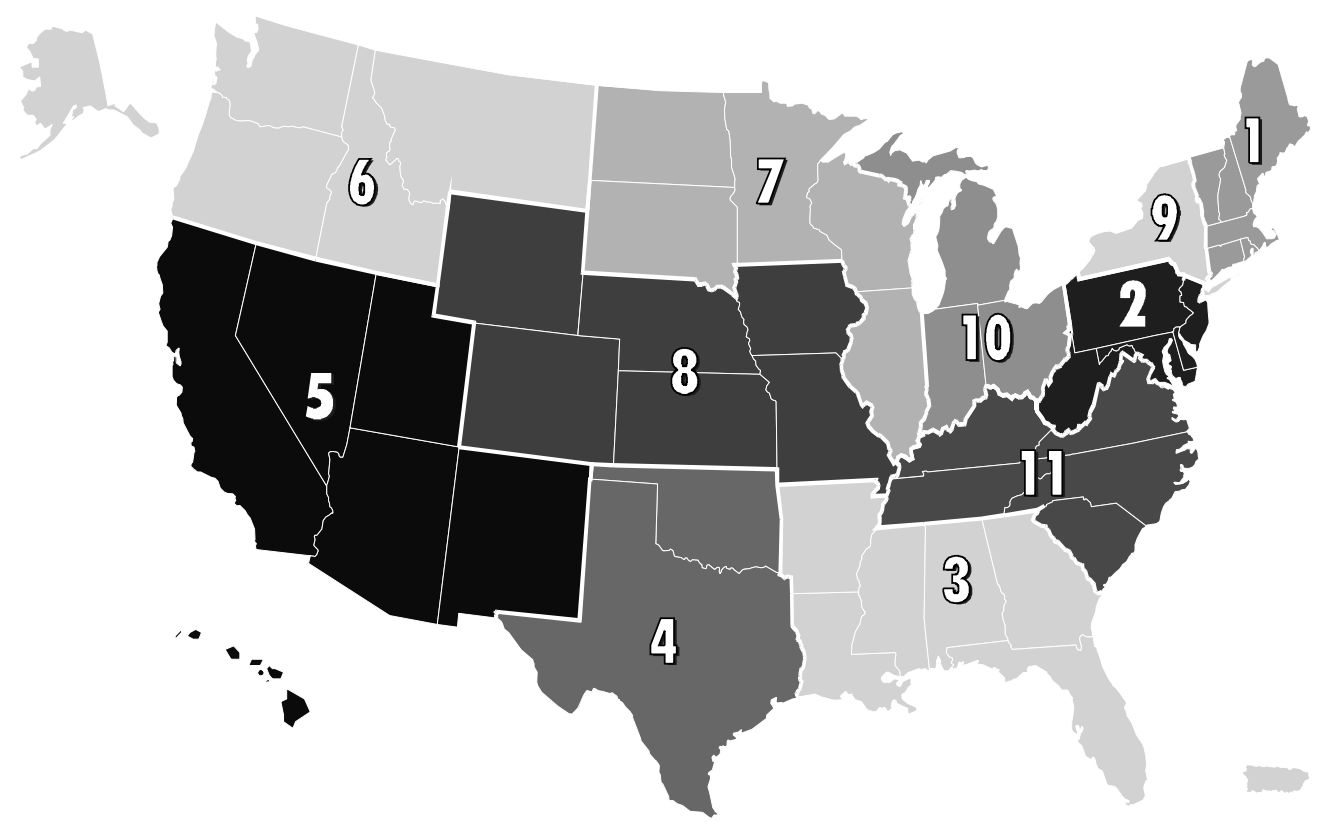

Figure 2: OPTN/UNOS regional map. Source: OPTN/UNOS.

7\% (Region 10) to a high of $30 \%$ (Region 7). This variability likely results from two factors. First, potential donor distribution is not uniform across the country. The number of potential organ donors varies widely by region. Second, the US system of organ donation relies on obtaining written consent for donation from next of kin. It is well documented that race, age, education, and other socioeconomic factors all influence the decision to give consent to donation; these factors are distributed unevenly across the country.

\section{Consent to Organ Donation}

The shortage of transplantable organs is a constant and frustrating reality. Two key factors are responsible for the critical shortage of transplantable solid organs in the United States. First, reliance on donations from deceased, brain-dead donors can provide only a limited number of potential donors; it has been estimated that no more than 15000 such donors are available each year $(1,2)$. Second, the rate of consent for organ donation by next of kin has limited the number of organs available for transplant. On average, no more than $50 \%$ of those families from whom donation is requested agree to donate (3-5). Increases in the total numbers of organs procured have resulted largely from an expansion of the donor pool (for example, accepting older patients as donors) and from improvements in procedures for referring and requesting organ donation from families of potential donor patients. Nonetheless, improving consent is still the most promising route to increasing the number of donated and recovered organs in the future.
Improving consent rates has been the target of a series of legislative and regulatory efforts. Organ donation in the United States is regulated by the Uniform Anatomical Gift Act (UAGA), drafted by the National Conference of Commissioners on Uniform State Laws in 1968 and modified in 1987. By 1973, it had been passed by all 50 states. Aimed at enabling individuals or their families to donate organs, UAGA also served to establish altruism and voluntarism as the bedrock of organ donation and procurement in the United States. This law recognizes the rights of individuals to donate by means of an organ donor card and gives the immediate family of a deceased person the option to donate. In 1973, the End-stage Renal Disease (ESRD) Program provided federal financial support for organ transplantation by funding $100 \%$ of organ procurement costs through Medicare. Federal organization and oversight of organ procurement were further developed in 1984, when Congress passed the National Organ Transplantation Act (NOTA). This law created the OPTN, which has the responsibility for setting standards and rules regarding the distribution of human organs procured in this country; the law also prohibited the sale of organs $(6,7)$.

The second major legislative effort to encourage the donation of organs is a set of laws collectively known as 'required request' laws. These laws directed hospitals to develop policies to assure that families of all donor-eligible patients would be given the option to donate. In 1986, HCFA made such requests a prerequisite for Medicare reimbursement (8), and the Joint Commission on Accreditation of Health Care Organizations (JCAHO) made it a requirement for hospital accreditation (9). Required 
request laws were established on the understandable, but unproven, assumption that if people were asked to donate, most would consent. Polls show that 99\% of Americans are aware of transplantation, and over $75 \%$ say they would donate their organs if asked (10-12). Unfortunately, required request laws have had little impact on the rate of consent to organ donation (13-16). A study by Siminoff et al. in 1995 (3) demonstrated that, on average, $85 \%$ of donor-eligible patients' families in two national regions were given the donation option, but only $48 \%$ actually consented. Other studies confirm these findings $(4,5)$.

As a further step, starting in 1998, HCFA required that hospitals must notify their local OPO about all deaths and imminent deaths and that families must be approached about donation in collaboration with the local OPO (17). Underlying this regulation (known as 'required referral' or 'routine notification') was the premise that health professionals alone were not effectively communicating with families about donation. This regulation, too, has had little impact on actual rates of consent to donation, although some regions have seen an increase in numbers of organs procured. Even with new regulations, altruism and voluntarism continue to be the cornerstones of organ procurement, along with a reliance on family consent to donation. Several proposals aimed at bypassing such dependence on these values have emerged. These include presumed consent, which allows health professionals to proceed with donation unless the patient had actively declined donation; mandated choice, which requires all citizens to register their willingness to donate organs; and financial incentives to families of future donors. At present, none of these proposals has been tested or demonstrated to be effective or socially acceptable. A new legislative effort, termed 'donor designation' or 'first-person consent', makes it possible for donation to occur without family permission if the deceased had a valid donor card, driver's license designation, or entry in a donor registry. Several states have recently enacted such laws.

Recent studies have emphasized the importance of the process of asking for organ donation (18). This process entails identification of donation-eligible patients and then the request. It is first necessary to identify that someone is a potential organ donor. Until recently, this process was almost completely in the hands of hospital health care providers. Data showed that the ability of health care providers to recognize a donor was variable. One study reported that $73 \%$ of health care providers were able to recognize a donor-eligible patient when presented with one (3). To address this problem, the 1998 HCFA regulations required that the local OPO be called about each hospital death. This should have immediately increased the number of donors, even without increasing the actual rate of consent, by guaranteeing that more eligible patients' families would be asked to donate. However, the data collected nationally show uneven results. Some
OPOs have made significant gains in procurement since 1998, though others have not. Moreover, data from a study of 30 OPOs conducted by the Association of Organ Procurement Organizations (AOPO) show that referral and request rates vary widely, ranging from $65 \%$ to $99 \%(19)$.

Different practices of discussing and obtaining consent from families have been widely debated and are the subject of some controversy. Factors such as when the request should be made, who should request organ donation, what should be discussed with the family, and how (or if) families who initially refuse organ donation should be reapproached, have all received attention. Some strategies, however, have not proven fruitful or have not been confirmed. For example, studies of timing of the donation request conducted in the early 1990s suggested that separating the request for donation from the pronouncement of death would create a significant rise in consent rates $(20,21)$. However, more recent studies have revealed that the issue is more complex and that raising the issue of organ donation with families earlier in the course of the patient's hospitalization-especially at the outset of determining brain death-may be the most useful practice $(22,23)$.

It has been suggested that families often refuse to consent to organ donation because they are concerned about mutilation of the body (24). A recent study found that families were more likely to donate when this issue was discussed openly rather than avoided $(3,25)$. Additionally, spending more time with families and discussing specific issues about organ donation were significantly associated with consent to donation. Families who spent more time and discussed more donation-related issues were five times more likely to donate (3).

The 1998 regulations also sought to guarantee that experienced requesters speak with families. Again, recent data indicate this will be a fruitful strategy if successfully implemented. For example, an earlier study found that health care providers who rated themselves as more uncomfortable speaking with families about organ donation were less likely to obtain consent than those who reported themselves as comfortable with discussing the topic and answering the family's questions (26). Moreover, Siminoff's recent study reports that patients' health care providers were unable to predict the family's initial reaction to the request to donate organs in over $50 \%$ of cases. Most important, if the patient's primary health care providers were incorrect in understanding whether the family might or might not want to donate, the family was less likely to donate. This emphasizes the need for families to meet with an experienced requester and for OPOs to consider reapproaching families who initially deny the request. This same study found that families who met with OPO requesters were three times more likely to donate than those who did not (3). 
Consent to organ donation by families of brain-dead patients has been a formidable barrier to maximizing the numbers of solid organs available for transplant in the United States. Despite public opinion polls reporting that more than $75 \%$ of the American public is willing to donate $(10,11)$, fewer than half choose to donate a family member's organs when asked. Legislative efforts have yet to close the gap between donor potential and organs procured. Studies now indicate that the process itself is of critical importance. Appropriate training and hospital donation development are needed to improve performance in the procurement of organs from deceased donors. Closer monitoring of consent rates nationally is needed to help guide policy and practice. At present, there is no national system for reliably and accurately measuring and reporting consent rates. Development and institution of such a reporting system would be helpful in making meaningful progress on this issue.

\section{Trends in Consent for Organ Donation, Recovery, and Disposition}

An assessment of the trend in organ donation requires distinction between the various steps involved in the donation and transplantation processes. Organ donation is said to have occurred effectively when the donor, the next of kin, or the designated survivor execute a consent for donation. Recovery implies surgical devascularization and removal of the organ from the body of the donor. By definition and practice, recovery and nonrecovery of organs applies only when consent for organ donation has been successfully executed. A recovered organ may be engrafted into a recipient (transplanted organ), used for research or other purposes, or discarded. Each of these outcomes (donation, recovery, transplantation, and discard) may be the final fate of an organ from a potential donor. None of these outcomes is rare.

The large proportional increase in living organ donation that started in the early 1990s is widely recognized as a major advancement in improving the supply of transplantable organs. However, it is not fully appreciated that during the same period, the increase in cadaveric organ donation was equally large, despite a lack of any noticeable increase in death rates among potential cadaveric organ donors. The total number of organ donors increased by $78 \%$ from 7092 in 1992 to 12607 in 2001. This rise consists of a $154 \%$ increase in living donors ( 2572 in 1992, 6526 in 2001) and a 35\% increase in deceased donors (4520 in 1992, to 6081 in 2001). Since the average deceased donor provided 3.6 organs, the total increase in recovered cadaveric organs from 1992 to 2001 was substantially higher (5967) than the increase in organs from living donors (3954) during the same period (Table 1). Thus, the 35\% increase in deceased donors between 1992 and 2001 produced more organs than the
Table 1: Trends in recovered organs from deceased and living donors, 1992-2001

\begin{tabular}{lll}
\hline & $\begin{array}{l}\text { Deceased } \\
\text { donor organs }\end{array}$ & $\begin{array}{l}\text { Living } \\
\text { donor organs }\end{array}$ \\
\hline 1992 & 16040 & 2572 \\
1993 & 18117 & 2905 \\
1994 & 19279 & 3102 \\
1995 & 19772 & 3475 \\
1996 & 19726 & 3754 \\
1997 & 20119 & 4035 \\
1998 & 20884 & 4501 \\
1999 & 21207 & 4838 \\
2000 & 21579 & 5738 \\
2001 & 22007 & 6526 \\
\hline
\end{tabular}

Source: 2002 OPTN/SRTR Annual Report, Tables 1.1, 1.2.

corresponding threefold increase in living donors. These findings bear reiteration for three reasons. First, there has been a substantial increase in cadaveric organ donation, though it is still far outpaced by the increase in the number of patients who need organ transplantation. Second, a small increase in the number of deceased donors translates into a larger impact on the availability of transplantable organs because of the potential for multiple organs from a single deceased donor. Third, the concerted efforts of various agencies and the public to promote organ donation appear to correlate with the higher number of donors, as evidenced by the appreciable increases in the numbers of organs from both living and deceased donors.

The aggregate increase in organ donation belies different organ-specific pictures largely because of the additional implications inherent to the organ donor source. Deceased donors are the only feasible source of heart donation and by far the single most important source of livers, lungs, intestinal organs and pancreata. Nearly all living donors gave kidneys (92\%) or liver segments (8\%); for these two organs, living donation has contributed greatly to overall transplantation increases over time. In contrast, the number of deceased heart donors has steadily decreased over time, dropping by $10 \%$ from a peak of 2525 in 1994 to 2275 in 2001. Between 1992 and 2001, the number of donated intestines, lungs, and pancreata increased by $448 \%$ (21 to 115) for intestine, 76\% (from 526 to 924) for lung, and $81 \%$ (1007 to 1823) for pancreas; virtually all of these increases came from deceased donors.

The prompt identification of potential deceased donors, optimal medical management, and successfully executed consent for organ donation may not ultimately result in organ recovery. Reasons for increased nonrecovery of organs have not been well studied. However, to be fully informative, the trends in nonrecovery should be considered in the context of the overall increase in cadaveric organ donation highlighted above. A large fraction of organs for which consent for donation was obtained were not recovered. In 2001, 40465 cadaveric organs 


\section{Nathan et al.}

were donated, $54 \%$ of which (22 007) were recovered. In 2001, nonrecovery was highest for intestines and lowest for kidneys: $97 \%(n=3895)$ of intestines and $7 \%(n=839)$ of kidneys were not recovered. The proportion of nonrecoveries for each organ in 2001 is shown in Figure 3. The single most important cause of nonrecovery is a determination of poor organ function/infection. The proportions of nonrecoveries for which poor organ function/infection was cited ranged from $26 \%$ (intestine) to $72 \%$ (lung). As a percentage of the total numbers of donated organs, the overall rate of nonrecovery has increased over time as the number of donated organs has increased. The percentage change in the number of nonrecovered organs between 1992 and 2001 was as follows: pancreas up 23\%; heart up $66 \%$; liver down 17\%; and kidney up 121\%. In 1992, 75\% (21 out of 28) of consented intestinal organs were recovered; this proportion dropped to less than 3\% (115 out of $4010)$ in 2001 . The higher nonrecovery rates of all organs except liver may reflect increased utilization of older donors, who are more likely to have poor organ function cited as the reason for nonrecovery.

\section{Deceased and Living Donor Characteristics}

\section{The supply of donors}

The number of deceased and living donors for all organs (see Figure 4) was 12607 in 2001, an 8\% increase over the previous year. From 1996 to 2001, the number of all organ donors increased at an average rate of $7 \%$ per year (see Figure 5). A large part of this increase in donors is attributable to increases in the number of living donors; 2001 was the first year in which living donors outnumbered deceased donors. In 2001, living donors made up just over half (52\%) of all donors, while in 1996 they made up only $41 \%$ of the total. Total living donors have been increasing 12\% per year since 1996 (see Figure 5); in contrast, deceased donors increased by $2 \%$ per year in the same period. Total recovered cadaveric organs have been increasing at a somewhat slower rate. In contrast, the number of patients on the cadaveric organ waiting list has been increasing at $11 \%$ per year since 1996 .

The growth in living donors has been a major force in helping ameliorate the organ donor shortage in the United States. But in spite of this fortunate supply of living donors, the need, as measured by persons on the waiting list, is growing faster. Despite $7 \%$ annual growth in the total donor supply from 1996 to 2001, the waiting list grew by $11 \%$ per year over the same period (Figure 5).

As noted above, living kidney donors represent the great majority of living donors (92\% in 2001); living liver donors represent almost all of the remainder. The number of living kidney donors rose at a substantial rate of $10 \%$ per year from 1996 to 2001, with some signs that the rate of growth may be increasing (up 12\% between 2000 and 2001). Living liver donors, while fewer in absolute

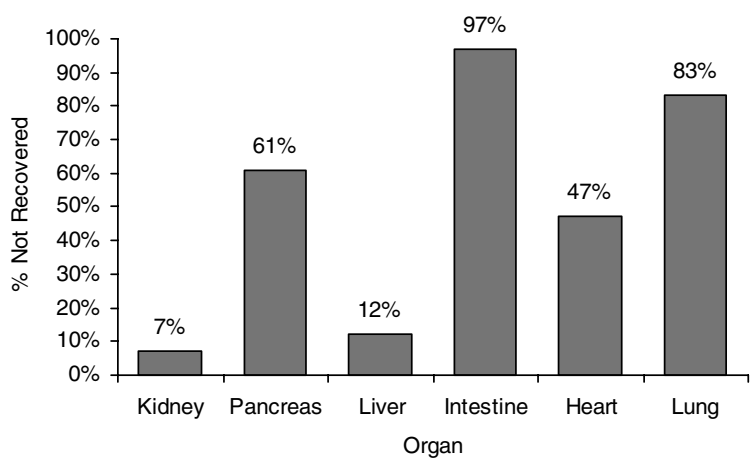

Figure 3: Nonrecovery of consented organs, 2001. Source: 2002 OPTN/SRTR Annual Report, Tables 3.1, 3.3, 3.4, 3.6, 3.7, 3.9, $3.10,3.12,3.13,3.15,3.16,3.18$.

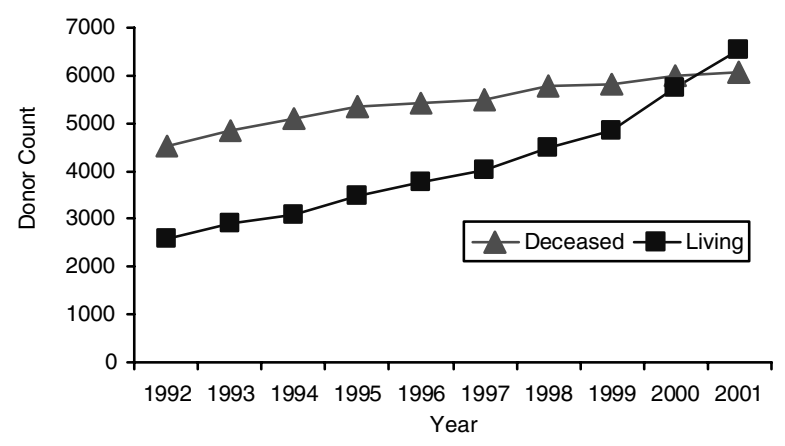

Figure 4: Deceased and living donors, 1992-2001. Source: 2002 OPTN/SRTR Annual Report, Table 1.1.

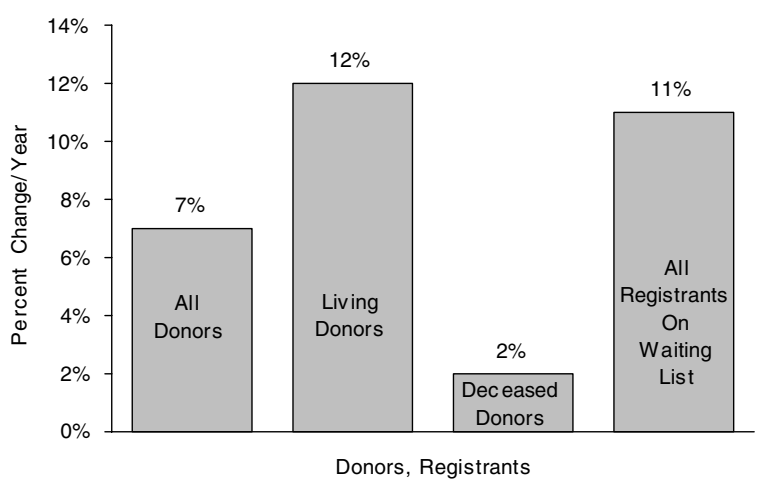

Figure 5: Annualized rates of change in organ donation statistics, 1996-2001. Source: 2002 OPTN/SRTR Annual Report, Tables 1.1, 1.3.

number than kidney donors, have increased at dramatic rates: From 1996 to 2001, the rate of growth was $42 \%$ per year, with $35 \%$ growth seen in the most recent year. 


\section{Living Donor Characteristics}

As shown in Figure 6, average donor age is in the mid-30s. Living donors are, on average, a year older than deceased donors. The average age of deceased donors rose by 2.4 years between 1996 and 2001, but living donors did not show much change in age over the same period. As shown in Figure 7, living donors are more likely to be female (approximately 58\%), while deceased donors are substantially more likely to be male. Between 1996 and $2001,41 \%$ of deceased donors were female and $59 \%$ were male. These proportions have not changed much over the last 5 years. Likewise, donor race (Figure 8 ) has not shown much change over the last 5 years, with $79-82 \%$ of living donors being white. Deceased donors were also predominantly white (85\%).

Donor blood type (Figure 9) has a substantially different distribution by donor source than does donor race. ABO blood type $O$ made up $66 \%$ of living donors but only $47 \%$ of deceased donors. The opposite pattern occurs for blood type A donors, who made up $26 \%$ of living donors and $38 \%$ of deceased donors. Blood type B represented approximately $7-12 \%$ of donors. The cumulative percentage of $A, B$, and $O$ type donors represented $99 \%$ of the living donors and $97 \%$ of the deceased donors. Donors of blood type $A B$ were a small percentage of both living and deceased donors.

The trend in the relation of living donors to recipients between 1992 and 2001 may at first appear confusing (Figure 10). The reason is that the total number of donors in certain categories has remained relatively constant while the total count of living donors has increased rapidly; as a result, the fairly stable counts of living donors have become a decreasing fraction of the total. For example, the total annual number of parental living donors has been relatively constant at 700-800 donors per year over the last 10 years. During this same period, the total count of living donors has increased substantially, so that the proportion of parents dropped from $26 \%$ of the total in 1992 to $13 \%$ in 2001 . From 1992 to 2001, the largest increase in living donors-both absolutely and relatively-occurred in the number of unrelated individuals, which increased 10-fold, from 159 donors to 1596 donors. As a fraction of the total, unrelated individuals increased from $6 \%$ to $24 \%$ of the total living donors over the same period.

\section{Deceased Donor Characteristics}

The total number of organs from deceased donors increased by less than $2 \%$ from 2000 to 2001 . This small increase was primarily influenced by the additional $2 \%$ of donors who also provided a liver and, to a lesser degree, the $34 \%$ increase in the number of intestinal donations. Figure 11 compares percentage changes in organ donation to percentage changes in the United States population

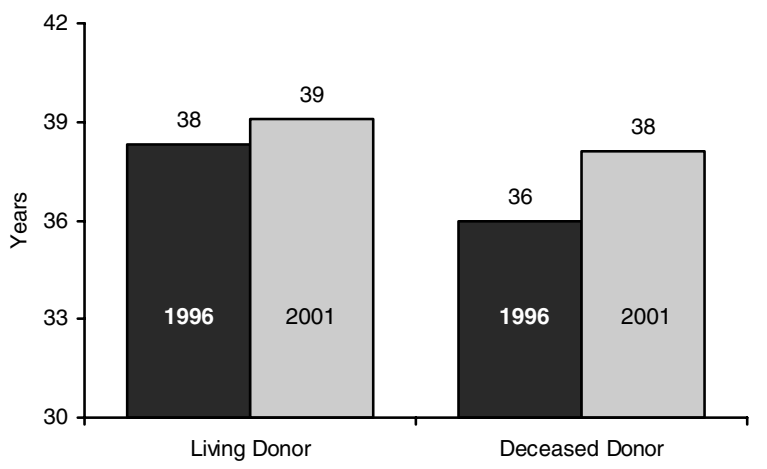

Figure 6: Average donor age, by living or deceased donor, 1996 vs. 2001. Source: SRTR Data Analysis, August 2002.

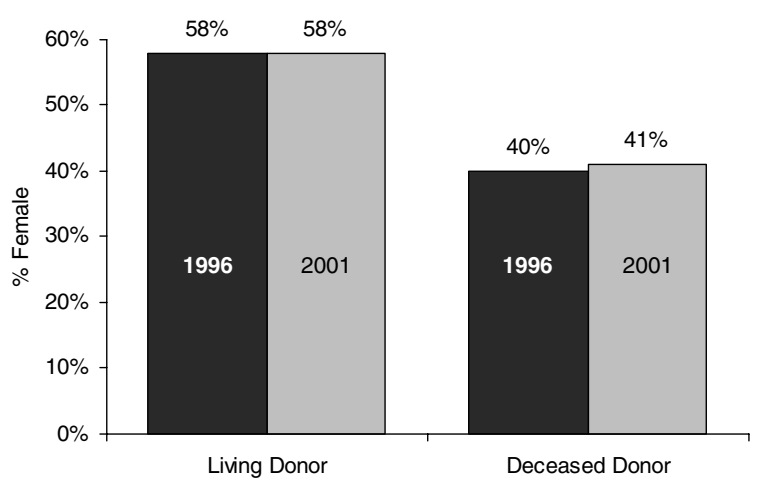

Figure 7: Donor sex, by living or deceased donor, 1996 vs. 2001. Source: 2002 OPTN/SRTR Annual Report, Tables 2.1, 2.8.

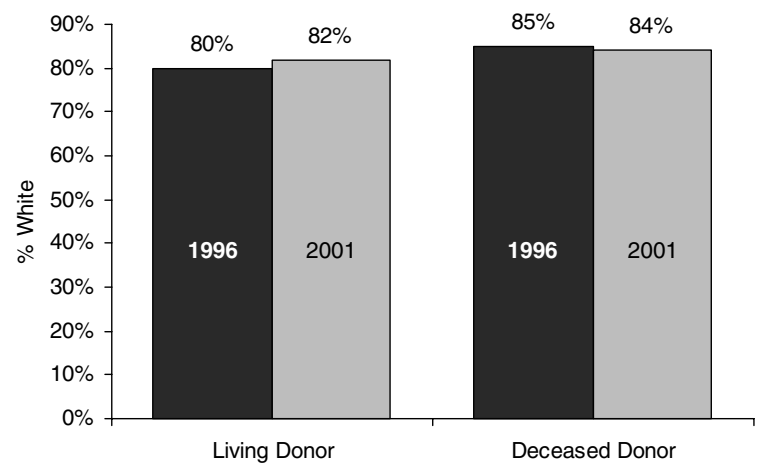

Figure 8: Donor race, by living or deceased donor, 1996 vs. 2001. Source: 2002 OPTN/SRTR Annual Report, Tables 2.1, 2.8.

$(27,28)$. This figure contrasts the wide annual variability in the number of deceased donors against the steady growth of the general population. The number of cadaveric kidney donations changed little between 2000 and 2001; a $40 \%$ rise in the number of nonheartbeating donors offset a decline in the number of kidneys from heartbeating donors. 


\section{Nathan et al.}

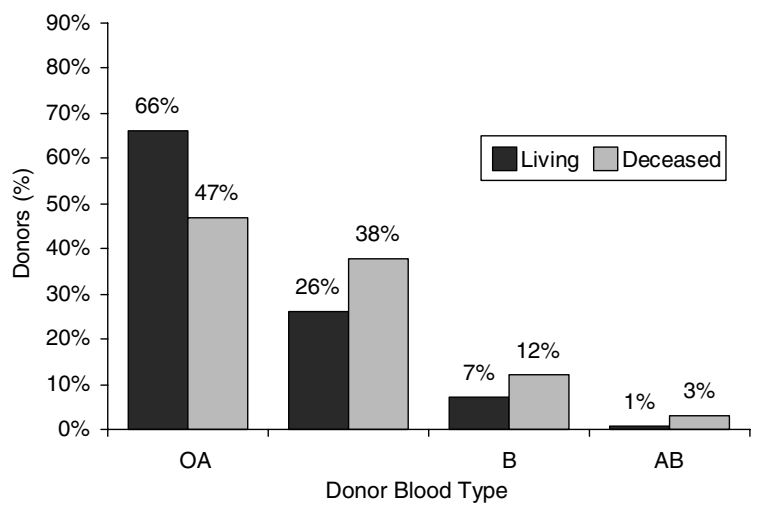

Figure 9: Donor blood type, by living or deceased donor, 2001. Source: 2002 OPTN/SRTR Annual Report, Tables 2.1, 2.8.

\section{Deceased donor age}

The deceased donor profile continues to shift away from the young adult who dies from a traumatic head injury to the older adult who dies from a cerebrovascular event. Figure 12 demonstrates the progressive increase in the median age of deceased donors over the past 10 years, which has exceeded that of the general population since $1996(29,30)$. From 2000 to 2001, the numbers of donors aged $1-10$ years, $18-49$ years, and 65 years and older rose. On a percentage basis, donors over 65 recorded the largest increase (9\%) between 2000 and 2001 but only comprised 44 additional donors. Donors aged 18-34 years showed the greatest increase in actual numbers, with 78 more than the previous year. In 2001, $16 \%$ of all donors were younger than 18 , compared with the pediatric segment $(26 \%)$ of the general population (31). On a percentage basis, 1999 and 2000 represented a 10-year low for pediatric donors at $17 \%$. In 2001, the percentage of pediatric donors increased to $19 \%$.

\section{Deceased donor race and ethnicity}

The racial makeup of the deceased donor population showed some degree of change between 2000 and 2001. While organs from white donors increased by only $1 \%$, donations from other races increased by $8 \%$ for the same period. All minority donor categories registered numeric and percentage increases in 2001, but it is important to note that the number of donors with race 'unknown' decreased over the same period. This shift may represent more accurate reporting of demographic data for minority donors. The demographic distribution of the deceased donor population essentially matches that of the general population demographics gathered by the 2000 US Census (Figure 13) (30).

It is also important to note that total minority donations also increased by 56\% from 1992 to 2001, while the number of white organ donors increased by $32 \%$ over the same period. Donor ethnicity remained relatively

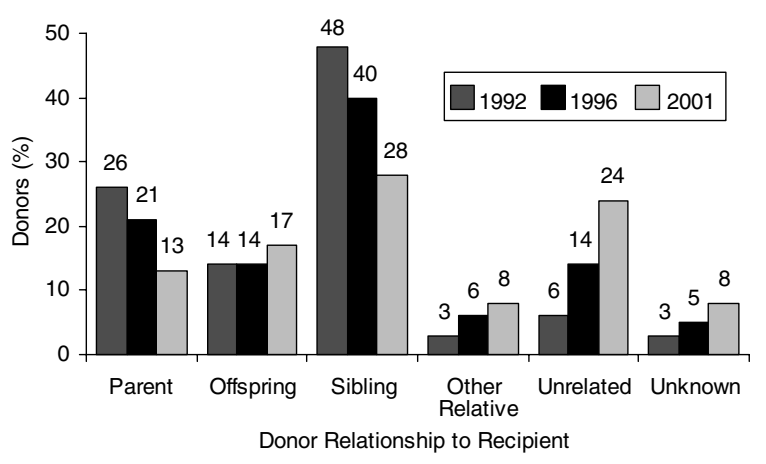

Figure 10: Living donor relationship to recipient, 1992, 1996 and 2001. Source: 2002 OPTN/SRTR Annual Report, Table 2.8.

unchanged in 2001, and differences in data collection over time currently make it difficult to draw any useful conclusions on this point.

\section{Deceased donor gender}

The distribution of deceased donors by gender changed little in 2001, though it has become more representative of the US general population in the past decade (32). The differences between the organ donor gender distribution and that of the general population (for example, $59 \%$ of all deceased donors are male, $49 \%$ of the general population is male) are in part attributable to variations in cause of death between the sexes and gender differences in granting organ donation consents (33).

\section{Cause, circumstance, and mechanism of death}

Figure 14 contrasts the cause of death for deceased donors in 2001 and 1995. In 2001, there were 695 donations resulting from anoxic brain deaths, up 12\% from 2000 and up by 32\% since 1995-the fastest rise among the causes of death for deceased donors. The rise in anoxic deaths from 2000 to 2001 resulted primarily from the increased frequency of drowning $(+40 \%)$, drug

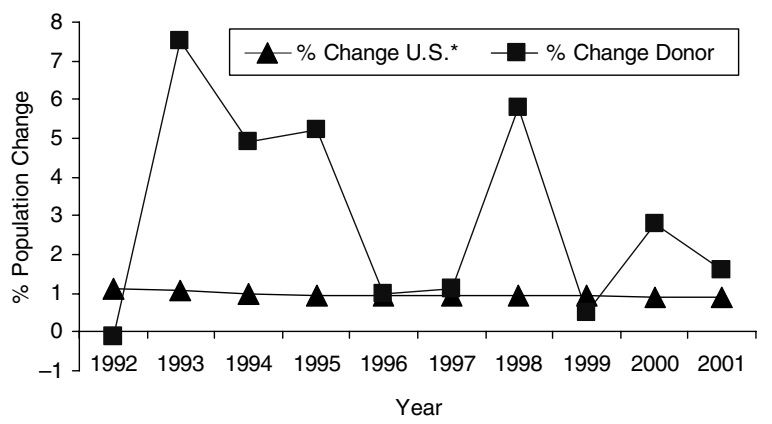

Figure 11: Annual deceased organ donor and US population changes, 1992-2001. Sources: 2002 OPTN/SRTR Annual Report, Table 1.1; *United States Census Bureau. US population change from $2000-2001$ is projected (30). 


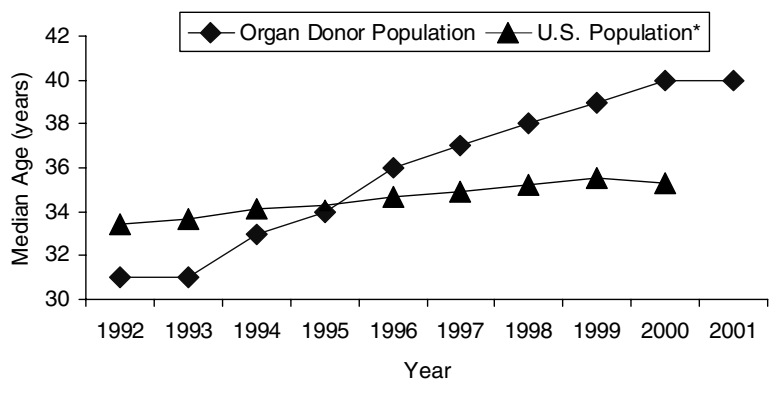

Figure 12: Median age of deceased organ donors and US population. Source: SRTR Data Analysis, August 2002; *United States Census Bureau. Census figures include projections.

intoxication $(+26 \%)$, and cardiovascular mechanisms $(+15 \%)$. Cerebrovascular deaths continue to lead as the primary cause for deceased donations $143 \%$ of all deceased donors in 2001). The remaining circumstances and mechanisms of death are either relatively unchanged or offer unremarkable trends.

\section{Deceased Donor Organ Recovery and Disposition}

\section{Kidney donation}

Kidney donation took place in $93 \%$ of cadaveric donations in 2001 (Figure 15). During the year, a record number $(n=593)$ and percentage $(11 \%)$ of kidney donations resulted from anoxic brain injury, including cardiovascular mechanisms ( $n=330)$, drug intoxication $(n=64)$, and drowning $(n=53)$. The total population of renal donors was also affected by a 7-year low in the number of donors from suicide, which have decreased by $21 \%$ since 1995 . Conversely, the number of donors resulting from child abuse increased by $30 \%(n=52)$. Due to surgical restrictions associated with younger pediatric kidneys, the recovery rate of kidneys from pediatric donors (age $<18$ ) is lower than those observed for other types of organs and well below the rate of this age group's occurrence in the general population (Figure 16) $(31,34)$.

The record number of kidneys recovered in 2001 resulted in an overall transplant rate of $86 \%$. Of the recovered kidneys, $60 \%$ were transplanted locally and $26 \%$ were transplanted either in the region or nationally. Of the kidneys recovered and not used, 36\% were reported to have had adverse biopsy findings.

\section{Pancreas donation}

Nearly two-thirds (63\%) of pancreas donors in 2001 were between the ages of 11 and 34 years, and $90 \%$ were between the ages of 11 and 49 years. Along with a record number of pancreata being recovered from donors aged $18-34$ years $(n=843)$, the overall number of Hispanic/Latino pancreas donors increased by $48 \%$ from the previous year

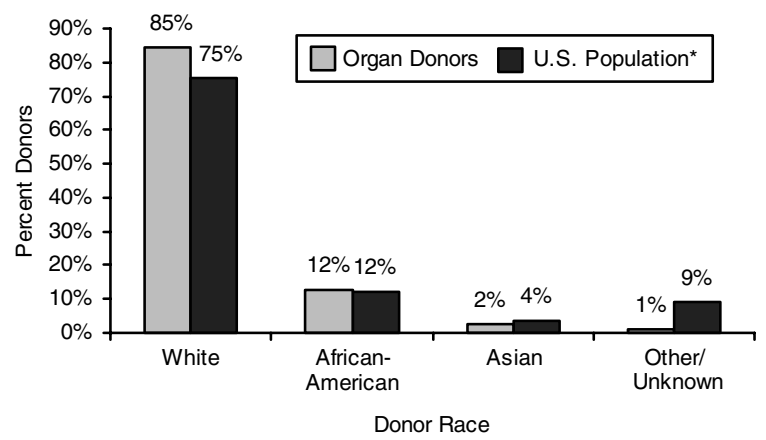

Figure 13: Race of deceased organ donors and US population, 2001. Source: 2002 OPTN/SRTR Annual Report, Tables 2.1, 2.8; * United States Census Bureau. Census figures include projections.

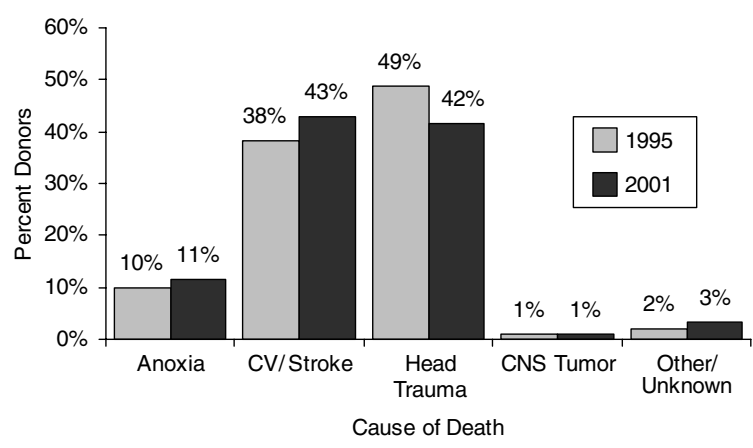

Figure 14: Percent cause of death for organ donors, 1995 vs. 2001. Note: 5362 deceased donors in 1995; 6081 in 2001. Source: 2002 OPTN/SRTR Annual Report, Table 2.1.

and more than doubled $(+124 \%)$ since 1995 . The main source of pancreas donors $(61 \%$ in 2001) continues to be head trauma patients involved in motor vehicle accidents. Less than one-third of all deceased donors had a pancreas recovered. The record number of pancreata

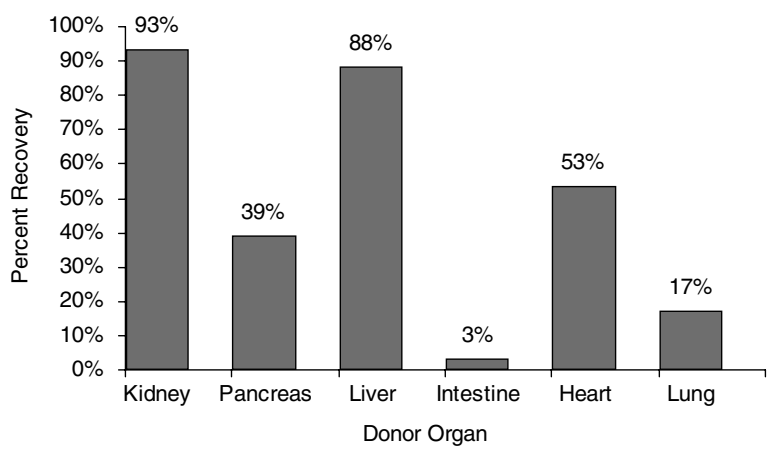

Figure 15: Organ recovery rates from deceased donors, 2001. Source: 2002 OPTN/SRTR Annual Report, Tables 3.1, 3.3, 3.4, 3.6, 3.7, 3.9, 3.10, 3.12, 3.13, 3.15, 3.16, 3.18. 


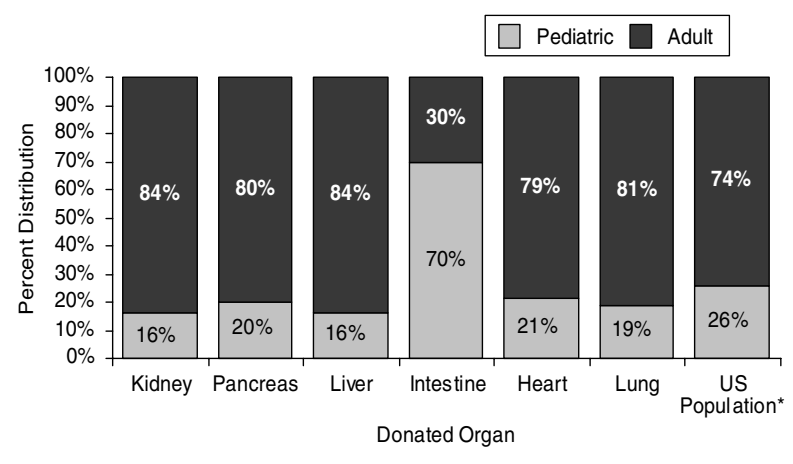

Figure 16: Distribution of cadaveric organ donations by age, 2001. Sources: 2002 OPTN/SRTR Annual Report, Tables 2.2, 2.3, 2.4, 2.5, 2.6, 2.7; * United States Census Bureau.

recovered and transplanted in 2001 ( $n=1394)$ was also accompanied by a 7-year low in organ utilization following recovery (Figure 17). These latter data underscore a great opportunity for improvement by the organ transplant system.

\section{Liver donation}

While the overall number of liver donations in 2001 increased in both volume $(+112)$ and percent $(+2 \%)$, the number of livers from donors younger than 18 years fell to a 9-year low. The additional volume of donations for 2001 came from donors older than 18 years; the record numbers of livers came from persons 65 years or older $(n=451)$, who made up $44 \%$ of the total increase in livers. Head trauma continues to be the primary cause of death for liver donors (43\%), though in 2001 it was closely followed by cerebrovascular deaths (43\%). A record number of livers $(n=5187)$ were recovered for transplant in 2001, and a record number of livers ( $n=3262$ ) were transplanted locally. Nearly half (47\%) of 262 livers recovered but not used were deemed unsuitable through biopsy findings.

\section{Intestine donation}

On a percentage basis, intestines are the fastest growing donated organ, increasing by a factor of 5.5 over the last decade. On a volume basis, however, the number of intestinal donations grew by only 29 additional organs last year and occurred in only $3 \%$ of all donations (Figure 15). The $34 \%$ increase in donations came mostly from donors younger than 5 years old $(+17)$ and $18-34$ years $(+12)$. More than half $(54 \%)$ of these donations came from mechanisms of death involving blunt head injuries and those related to gunshot wounds. As the indications for intestinal transplant are greater for pediatric patients, this form of donation continues to prevail within the group of donors younger than 18 years (Figure 16) (35). Because of the scarcity of pediatric intestine donors, most intestines $(72 \%)$ are recovered outside of the area in which they are transplanted (Figure 17).

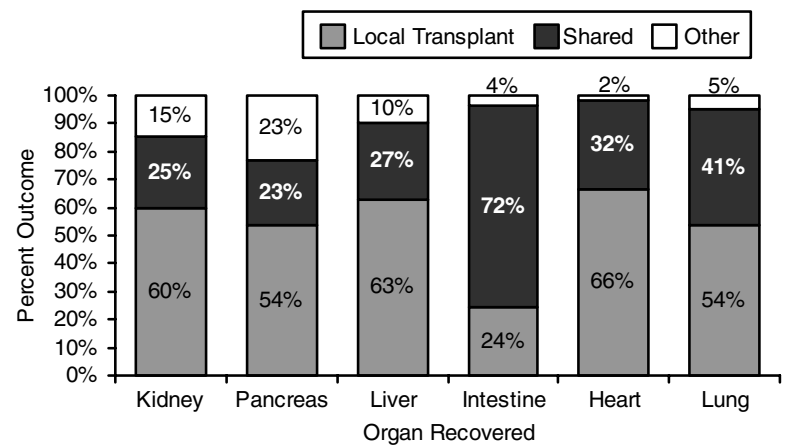

Figure 17: Cadaveric organ recovery outcomes, 2001. Source: 2002 OPTN/SRTR Annual Report, Tables 3.1, 3.4, 3.7, 3.10, 3.13, 3.16.

\section{Heart donation}

Heart donation volume fell by less than 1\% in 2001 and remains similar to the number donated 10 years ago. More than one-half of all heart donations are from donors with head trauma that resulted from motor vehicle accidents (33\%), suicide (11\%), homicide (9\%), and child abuse $(2 \%)$. Hearts have the highest local utilization of all organ types, with two-thirds (66\%) remaining in the OPO service area where they are donated (Figure 17). Inability to extend cold ischemic storage time during transport may be a prevailing factor in the high percentage of hearts transplanted locally.

\section{Lung donation}

While the number of lung donations increased by $8 \%$ in 2001, the overall volume of lung donations has not exceeded the number recovered in 1994. Last year, head trauma continued to be responsible for death in roughly one-half of all lung donations (52\%), with cerebrovascular causes achieving a new record volume $(n=327)$ and percentage (37\%) contribution. In 2001, $41 \%$ of all lungs recovered were shared regionally or nationally (Figure 17). Overall, lung donations occurred in only $17 \%$ of all cadaveric donations (Figure 15).

\section{Nonheartbeating Donors}

During the early years of successful human transplantation, organ donation entailed the removal of kidneys from patients whose heart had stopped beating. The first heart transplant, in 1967, was recovered from a nonheartbeating donor (NHBD). However, in 1968 organs began to be procured from patients who were declared dead based on brain-death criteria and whose circulation was maintained until the organs were recovered (36). In the 1970 s and 1980s, most centers abandoned the practice of recovering organs from NHBDs, since those organs were considered less desirable because of requisite warm ischemic time and higher rates of delayed graft function. However, 
in response to the growing waiting list for kidneys and other organs, transplant centers began to re-evaluate NHBDs as a source of abdominal organs (kidneys, livers, and pancreata) in the early 1990s. OPOs developed policies enabling hospitals to offer organ donation as an option for families deciding to remove a family member from life support because of a devastating, terminal neurological injury. Organ donation could only take place after families had made the decision to withdraw care and had given full informed consent for the donation. NHBDs carried out in this manner are defined as 'controlled' NHBDs and represent the majority of such donations in the United States. 'Uncontrolled' NHBDs occur when a patient who is being evaluated as a potential deceased donor has a cardiac arrest and cannot be resuscitated before brain death is determined.

The number of NHBDs rose from 42 in 1993 to 167 in 2001 , representing nearly $3 \%$ of all deceased donors in the United States in 2001. The number of OPOs recovering organs from NHBDs rose from 13 in 1993 to 33 in 2001 (Table 2). During that period, 43 OPOs participated in at least one NHBD procurement. In 2001, six OPOs procured more than 10 NHBDs, two OPOs procured 6-10, 25 OPOs procured 1-5, and 26 OPOs procured none (Table 3). For the most active OPOs procuring NHBDs in 2001, NHBDs represented an average of $10 \%$ of total donors; the range of NHBDs as a percentage of total deceased donors among all OPOs that procure NHBDs is 1-15\% (Table 3). Based on current data, if all 59 OPOs utilized NHBDs at the same rate as the most active OPOs procuring NHBDs, as many as 600 additional donors could be identified, yielding at least 1200 organs annually (37).

\section{Newer Initiatives In Organ Donation}

Living donations continue to increase from both related and nonrelated donors. Some regions have organized nontraditional programs for living donors. For example, in $\mathrm{New}$ England and Washington, DC, there are programs through which a patient who has a willing but incompatible living

Table 2: US OPOs-deceased donors and nonheartbeating donors, 1993-2001

\begin{tabular}{llcl}
\hline $\begin{array}{l}\text { Year of } \\
\text { recovery }\end{array}$ & $\begin{array}{l}\text { Total } \\
\text { donors }\end{array}$ & NHBDs & $\begin{array}{l}\text { OPOs with } \\
\text { NHBD } \geq 1\end{array}$ \\
\hline 1993 & 4861 & 42 & 13 \\
1994 & 5099 & 57 & 22 \\
1995 & 5362 & 64 & 22 \\
1996 & 5418 & 71 & 21 \\
1997 & 5479 & 78 & 19 \\
1998 & 5795 & 74 & 16 \\
1999 & 5824 & 87 & 20 \\
2000 & 5986 & 119 & 30 \\
2001 & 6081 & 167 & 33 \\
\hline
\end{tabular}

Sources: SRTR analysis, August 2002 and 2002 OPTN/SRTR Annual Report, Table 1.1.
Table 3: OPOs recovering organs from nonheartbeating donors, 1999-2001

\begin{tabular}{lccc}
\hline \multirow{2}{*}{$\begin{array}{l}\text { No. of NHBDs } \\
\text { per OPO }\end{array}$} & \multicolumn{3}{l}{ No. of OPOs (Total No. of NHBDs) } \\
\cline { 2 - 4 } & 1999 & 2000 & 2001 \\
\hline $1-5$ & $16(41)$ & $23(46)$ & $25(60)$ \\
$6-10$ & $3(23)$ & $4(29)$ & $2(17)$ \\
$>10$ & $1(24)$ & $3(47)$ & $6(93)$ \\
Total & $20(88)$ & $30(122)$ & $33(170)$ \\
NHBDs as & $1-8 \%$ & $<1-16 \%$ & $<1-15 \%$ \\
percentage of donors & & &
\end{tabular}

Source: SRTR analysis, August 2002.

kidney donor can perform a paired exchange with a similar living donor/recipient pair. In other cases, a living donor can donate a kidney to a local pool of waiting list registrants and have the organ allocated as if the kidney were from a deceased donor. In return, a cadaveric kidney from that OPO's pool can be given to the patient originally slated to receive the living donor's kidney. Such innovations can help mitigate the growing need for organs.

Many initiatives in the United States aim to increase the number of organs from deceased donors. There are continuous efforts by almost all OPOs to review the medical records of the hospitals in their respective regions, with the purpose of determining whether potential organ donors are routinely being identified and referred to the OPO. This information, along with the hospitals' corresponding consent rates, is used by OPOs in an effort to improve donation rates at each hospital.

Twenty-one states now have donor registries; many are linked through driver's license bureaus or departments of motor vehicles, where individuals can designate their wishes to donate on their license. These designations are typically stored in a computerized database that can be accessed by the OPOs at time of death. Positive designations may be used as legal consent in many states; in other states it has made the consent process easier when discussing donation with the potential donor's next of kin.

\section{Conclusions}

This article provides an overview of the organ procurement system in the United States. Analyses of trends over the last decade revealed the following key findings. The total number of organ donors increased between 1992 and 2001. The number of living donors increased by a factor of 2.5; the number of deceased donors increased 35\%. In 2001, 40465 cadaveric organs were donated, 54\% of which (22007) were recovered. The average deceased donor provided 3.6 organs. Nonrecovery was highest for intestines (97\%) and lowest for kidneys $(7 \%)$. The deceased donor profile has continued to shift away from the young adult who dies from a traumatic 
head injury to the older adult who dies from a cerebrovascular event. The advent of living liver and lung donations has offered new options for candidates needing these organs. The most notable development among living donors is the 10-fold increase in unrelated donors over the decade, to a total of 1596 in 2001.

\section{References}

1. Nathan HM, Jarrell BE, Broznik B et al. Estimation and characterization of the potential renal organ donor pool in Pennsylvania. Report of the Pennsylvania Statewide Donor Study. Transplantation 1991; 51: 142-149.

2. Evans RW, Manninen DL. US public opinion concerning the procurement and distribution of donor organs. Transplant Proc 1988; 20: 781-785.

3. Siminoff LA, Arnold RM, Caplan AL, Virnig BA, Seltzer DL. Public policy governing organ and tissue procurement in the United States: results from the National Organ and Tissue Procurement Study. Ann Intern Med 1995; 123: 10-17.

4. Gortmaker SL, Beasley $\mathrm{CL}$, Sheehy $\mathrm{E}$ et al. Improving the request process to increase family consent for organ donation. $J$ Transplant Coordination 1998; 8: 210-217.

5. Beasley CL, Capossela CL, Brigham LE, Gunderson S, Weber P, Gortmaker SL. The impact of a comprehensive, hospital-focused intervention to increase organ donation. J Transplant Coordination 1997; 7: 6-13.

6. Prottas J. The Most Useful Gift. San Francisco: Jossey-Bass, 1994.

7. Sullivan R. The Uniform Anatomical Gift Act. In: Organ and Tissue Donation. Carbondale, IL: Southern Illinois University Press, 1996: 19-33.

8. Department of Health and Human Services. H.C.F.A. Hospital Protocols for Organ Procurement and Standards for Organ Procurement Agencies. 42 USC, 1986: 1320b-8.

9. Joint Commission on Accreditation of Healthcare Organizations. 1992 Joint Commission AMH: Accreditation Manual for Hospitals. Oakbrook Terrace, IL: JCAHO, 1992: 45, MA 1.3.9, MA 1.3.10.

10. The Gallup Organization. I. The American Public's Attitudes Toward Organ Donation and Transplantation. Boston, MA: The Partnership for Organ Donation, 1993.

11. Watt SM. How People Feel About Organ Donation. Los Angeles, CA: Lieberman Research, 1991.

12. Siminoff LA, Mercer MB. Public policy, public opinion, and consent for organ donation. Cambridge Q Healthcare Ethics 2001; 10: 377-386.

13. Anderson KS, Fox DM. The impact of routine inquiry laws on organ donation. Health Affairs 1988; 7: 65-78.

14. Miller TE. Required request legislation and beyond. J Transplant Coordination 1991; 1: 90-94.

15. Ohio Department of Health, R.L.F., Director. Required Request. Its impact on organ/tissue donation and transplantation in Ohio. A Report for Governor Richard F. Celeste and the 118th Ohio General Assembly: 1989.

16. Virnig BA, Caplan AL. Required request: what difference has it made? Transplant Proc 1992; 24: 2155-2158.

17. Department of Health and Human Services. H.C.F.A., Medicare and Medicaid Programs. Hospital conditions of participation: identification of potential organ, tissue, and eye donors and transplant hospitals' provisions of transplant-related data. Final rule. Federal Register 1998; 119 (Codified at 42 CFR S482.45).
18. Siminoff LA, Arnold RM, Hewlett J. The process of organ donation and its effects on consent. Clin Transplant 2001; 5: 39-47.

19. Conrad SL. AOPO Death Records Review Study. Presented at: AOPO Annual Meeting; Salt Lake City, UT. June 19, 2002.

20. Garrison R, Bentley $F$, Raque $G$ et al. There is an answer to the shortage of organ donors. Surg Gynecol Obstet 1991; 173: 391-396.

21. Cutler JA, David SD, Kress CJ et al. Increasing the availability of cadaveric organs for transplantation maximizing the consent rate. Transplantation 1993; 56: 225-228.

22. Niles PA, Mattice BJ. The timing factor in the consent process. J Transplant Coordination 1996; 6: 84-87.

23. Siminoff $L A$, Lawrence $R H$, Zhang A. Decoupling: What is it and does it really help increase consent to organ donation? Prog Transplant 2002; 12: 52-60.

24. Verble M, Worth J. Dealing with the fear of mutilation in the donation discussion. J Transplant Coordination 1999; 9: 54-56.

25. DeJong $W$, Franz HG, Wolfe SM et al. Requesting organ donation: an interview study of donor and nondonor families. Am J Crit Care 1998; 7: 13-23.

26. Siminoff LA, Arnold RM, Caplan AL. Health care professional attitudes toward donation. effect on practice and procurement. J Trauma 1995; 39: 553-559.

27. US Census Bureau. Population Estimates Program. Population Division, US Census Bureau. Internet Revision Date February 14, 2000. http://www.census.gov/population/www/estimates/ popest.html

28. US Census Bureau. Population Projections Program. Population Division, US Census Bureau. Internet Revision Date February 14, 2000. http://www.census.gov/population/www/estimates/ popest.html

29. Scientific Registry of Transplant Recipients. Median cadaveric donor age in years between 1992 and 2001. Ann Arbor, Michigan: Scientific Registry of Transplant Recipients, 2002.

30. US Census Bureau. Population Estimates Program. Population Division, US Census Bureau. Internet Revision Date February 14, 2000. http://www.census.gov/population/projections/nation/ summary/np-t1.txt

31. US Census Bureau. Census Summary File 1. Internet Revision Date October 3, 2001. http://www.census.gov/population/ cen2000/phc-t9/tab01.txt

32. US Census Bureau. USA statistics in brief - population and vital statistics. Internet Revision Date May 9, 2002. http://www. census.gov/statab/www/poppart.html

33. Siminoff $L A$. Factors influencing families' consent for donation of solid organs for transplantation. JAMA 2001; 286: 71-77.

34. Strey C, Grotz W, Mutz C et al. Graft survival and graft function of pediatric en bloc kidneys in paraaortal position. Transplantation 2002; 73: 1095-1099.

35. Abu-Elmagd K, Reyes J, Bond $G$ et al. Clinical intestinal transplantation. a decade of experience at a single center. Ann Surg 2001; 234: 404-416, discussion 416-417.

36. Anonymous. A definition of irreversible coma. Report of the Ad Hoc Committee of the Harvard Medical School to Examine the Definition of Brain Death. JAMA 1968; 205: 337-340.

37. Jarrell $B E$, Nathan HM, Misiorowski RL. Increasing the renal donor pool. an estimate of the non-heart-beating cadaver pool. Abstract presented to The Society for Organ Sharing 2nd International Congress. Vancouver, BC, July 4-6, 1993. 